\title{
Velhez: o bom encontro entre vida e arte*
}


A velhice tem sido estudada, em particular nas sociedades ocidentais, por diferentes perspectivas e diversas realidades históricas e culturais. A partir do final do século XX, de acordo com Silvana Tótora (2015), aconteceu uma "explosão discursiva" em que a população de velhos aparece como um problema político. 0 termo velhice, nas práticas discursivas e sociais, denota, na maioria das vezes, um sentido negativo, visto que a velhice está associada à doença, perda da vitalidade, produtividade. Por conseguinte, usam-se termos tais como, melhor idade, idoso, maturidade, boa idade, como forma de escapar de estigmas e conferir uma cifra positiva para esse ciclo de vida, dos quais, ousamos dizer, podem servir mais como ações maquiadoras do que dar um estatuto positivo à velhice e ao envelhecimento. Além

* As ideias do texto partem da dissertação desses estereótipos, os discursos negativos

SOBRE VELHOS E VELHICES: Grandma Ade-

laide e um modo de vida outro na contemporaneidade (2019), sob orientação da profa. dra. Oriana Duarte, PPG-Design UFPE. 
se agravam quando o indivíduo velho adquire um sentimento de ser um peso para si, para os familiares e para a sociedade.

Diante dessa configuração no que diz respeito à velhice e ao envelhecimento, Silvana Tótora, professora e pesquisadora, a qual tem se debruçado há mais de dez anos em estudar esses temas, produziu um pensamento inédito e original em relação à velhice na contemporaneidade criando pontes e borrando fronteiras de diferentes áreas de conhecimentos, a saber, gerontologia, ciência política, filosofia, arte, literatura.

No entendimento da autora o enfrentamento da velhice é um problema atual, então delimita a "potência da velhice" como seu problema de pesquisa cujo eixo condutor é resistir aos discursos produzidos na atualidade sobre velhice e envelhecimento, vale acentuar, tanto os positivos quanto os negativos demasiadamente difundidos pela mídia. Assim, ela se norteia pelo problema da "potência da velhice" situado num campo ético-político, e além de analisar os dispositivos de poder atuais no gerenciamento da vida e da morte dos velhos, ela segue em direção ao um novo possível de libertação e resistência aos dispositivos que padronizam a vida da população de velhos e congelam as subjetividades na contemporaneidade e com isso produzir modos de vida outros, eis, uma ética da velhice como estética da existência. 


\section{AFETOS}

O corpo em Espinosa tem a mesma relevância que o espírito ou pensamento. Não existe uma superioridade de um sobre o outro. Espinosa, ao levantar a proposição "não sabemos o que pode um corpo...", que depois Deleuze atualiza para "o que pode o corpo?", abala os altares da filosofia desafiando seus esforços de instituir a moral "no poder de dominar as paixões pela consciência, ou de superioridade da alma sobre o corpo". (TÓTORA, 2015, p.34). Deste modo, se entende que o corpo também é dotado de potência capaz de sobressaltar ao domínio de um saber firmado no privilégio do plano da consciência. Quando um corpo encontra outro corpo, cada qual provido de sua potência, o resultado dessa relação forma um todo mais potente. A decorrência dessa relação são os afetos positivos ou negativos, alegria ou tristeza, e segundo as relações se compõem ou se decompõem nesta ordem. "Nossa potência ou nossa força de existir é aumentada ou diminuída de uma maneira contínua, sobre uma linha contínua, isto é o que chamamos afeto, o que chamamos existir" (DELEUZE, 2009, p.28).

Espinosa distingue moral da ética que por sua vez é distinta pelos bons e maus encontros. Essa atitude vai além de uma metodologia teórica trivial acarretando profundos efeitos de ordem prática para os seres humanos, produzindo alterações da sua potência de existir ou de agir. O bom encontro é quando um corpo é afetado por outro e vice-versa aumentando a sua potência de agir e provocando afetos de alegria. O mau encontro é encontrar um corpo que se relaciona mal com o seu, é quando um corpo tira a potência de ação do outro provocando afetos de tristeza. (TÓTORA, 2015, p.35).

O pensamento moral é estabelecido alicerçado em valores transcendentes de bem e de mal que pretende codificar, controlar o fortuito, regular os atos trocando a potência pelo dever. $O$ dever determina tanto as condutas coletivas quanto as individuais de uma sociedade através de leis ou normas. Está contido nas leis, portanto, um sentido moral cujo preceito é o dever e sua consequência, a obediência. Um mecanismo do juízo moral é instituir prêmios e punições, assim envelhecer é um mal destinado àqueles que não cumpriram o receituário correto de vida, o que coloca os idosos no centro de insistentes investidas de fórmulas de modos de viver. Por isso a urgência de um pensamento 
ético que se desloca do princípio e do dever, e consequentemente da obediência, para um conhecimento que se associa aos modelos de existência que se filiem aos experimentos dos encontros. Dos bons encontros, aliás.

A ética do encontro trata de uma arte de construir, vivenciar e experimentar bons encontros e provocar de modo ativo os afetos de alegria. Tótora (2015) atribui ao qualitativo ativo/a uma outra acepção desprendida de contornos rígidos e aponta uma perspectiva que se contrapõe à modelos instituídos.

Nessa perspectiva, podem ser experimentados modos de associação ou de sociabilidade livres de formas instituídas. É possível compor uma sinfonia em que a variação de ritmos e as intensidades de afetos se recriam cada vez de forma diferente, em que o devir impeça a fixação de identidades por segmentosvelhos, jovens, criança- ou por funções no interior das instituições. As diferenças compõem-se sem dominação. (TÓTORA, 2015, p.41).
Enquanto não compreendermos do que somos capazes estaremos expostos a maus encontros, e que esse conhecimento só é adquirido através da experimentação, então, para isso, é necessário que estejamos dotados de nossa potência de agir. Ademais, é preciso atentar para os afetos negativos que nos diminuem a potência de ação (as paixões negativas: as da tristeza). Isso não quer dizer que somos coagidos a viver sem tristeza ou viver desesperadamente rindo de tudo, afinal viver também acarreta tristeza e dor. Todavia, não nos esqueçamos de que incontáveis relações produzem afetos de tristeza porque são agenciamentos daqueles que intentam nos governar sob o exercício do domínio e até mesmo da escravidão.

É digno de nota o fato de que se estar aberto aos afetos não significa a falta de um filtro. A força se diferencia da fraqueza pelo princípio seletivo. A velhice como uma afirmação da vida, "o dizer sim à vida", passa ao largo de uma atitude de conformismo e contentamento com as coisas que existem desprovidos da capacidade de avaliar e selecionar. Para viver nesse mundo acelerado que beira a um esgotamento, mas que também possibilita bons encontros, implica em dizer sim e não. Esse sim de afirmação 
da vida não significa estar exposto a todos os estímulos tenazes e intrusivos, também não significa que não se aprendeu a dizer não, tampouco que tem que consentir tudo.

Ainda mais, porque todo esse excesso de estímulos, aceleração extrema da vida da nossa atualidade, não atinge os velhos da mesma maneira. 0 tempo das pessoas mais velhas é outro, mesmo que muitas delas tenham um estilo de vida mais agitado, estejam, de alguma forma, inseridas nas redes sociais e em relação com diversas tecnologias, as exigências e os estímulos são de outra ordem. Tótora (2015) argumenta que perdemos a experiência com o tempo. Ninguém comanda sua própria velocidade. Essa aceleração que vivemos é, em grande medida, inatingível pelo velho.

Há uma economia do corpo na velhice, exprimível nos gestos contidos, porém gestos intensos, potentes e focados. Não se pode mais na velhice fazer tudo, por isso é preciso uma seleção que reduza a superfície exposta ao acaso dos encontros, mais especificamente aos maus encontros (...). Tudo isso vale para aquelas velhices que se afirmam nas suas singularidades. (2015, p.171).

O corpo da velhice é mais vagaroso, é também esse o corpo que aqui está exposto em adelaide enquanto se move e pulsa com suas bengalas e andador, um corpo que no bom encontro com sua neta produz um modo de vida diferente e escapa do padrão de normalidade esperado na velhice. Adelaide, na sua singularidade, encena, experimenta gestos, expressões, inventa, produzindo novos possíveis e habita o mundo de maneira poética, no que Tótora chama de 
"um habitar como um devir singular em meio à cotidianidade".

Ademais, a autora elege a própria velhice como uma estratégia de afrontamento do tempo presente atribuindo à velhice uma afirmação, e contrapõe a essa aceleração da época atual uma perspectiva de assumirmos a lentidão da velhice. Assumir a vagareza da velhice, portanto, é contrapor-se a essa aceleração incessante, é o filtro do "não", do desaceleramento. Inventar novos modos de vida requer outra relação com o tempo, contudo conferir um ritmo próprio significa uma invenção do tempo como potência do acontecimento da vida - $a$ velhice torna-se obra de arte:

Tudo é uma questão de perspectiva e de devir, pois não existe uma velhice ideal. ou substantivada na identidade do sujeito velho. Experimentar a velhice é poder deslizar sobre os problemas, sofrimentos, dores e doenças como artistas que inventam saídas alegres e impensadas. Tornar a vida necessária não é sublimação, muito menos resignar-se; ao contrário, é não acusá-la ou praguejar a existência ou os viventes, tampouco projetar modelos idealizados. Há certa grandeza na afirmação da velhice. (TÓTORA, 2015, p.221).

\title{
O BOM ENCONTRO
}

\author{
"A gente tem que começar a pensar essa palavra \\ invisível, o conceito de invisível. Primeiro de tudo, \\ invisível para quem? E segundo que ninguém é invisí- \\ vel e transparente. A gente tem que começar a pensar \\ e analisar o olhar do outro ou a ausência de olhar do \\ outro." (IVÁNOVA, 2017).
}

Com essa (in)citação de Adelaide Ivánova, extraída da entrevista concedida em 2017, para a dissertação, iniciamos nossa travessia pelas fotografias de Adelaide. Por tal afirmação, Ivánova questiona 
Fotografia 1.

adelaide-10, Adelaide

Ivánova. Fonte: ade-

laideivanova.com/

projects/adelaide/. a invisibilidade de corpos velhos propondo uma reflexão sobre como olhamos ou deixamos de olhar esses corpos. É preciso trocar a lente para mudar o olhar ou enxergar melhor, e por isso talvez refletir e, quem sabe, até sentir diferente a experiência da velhice.

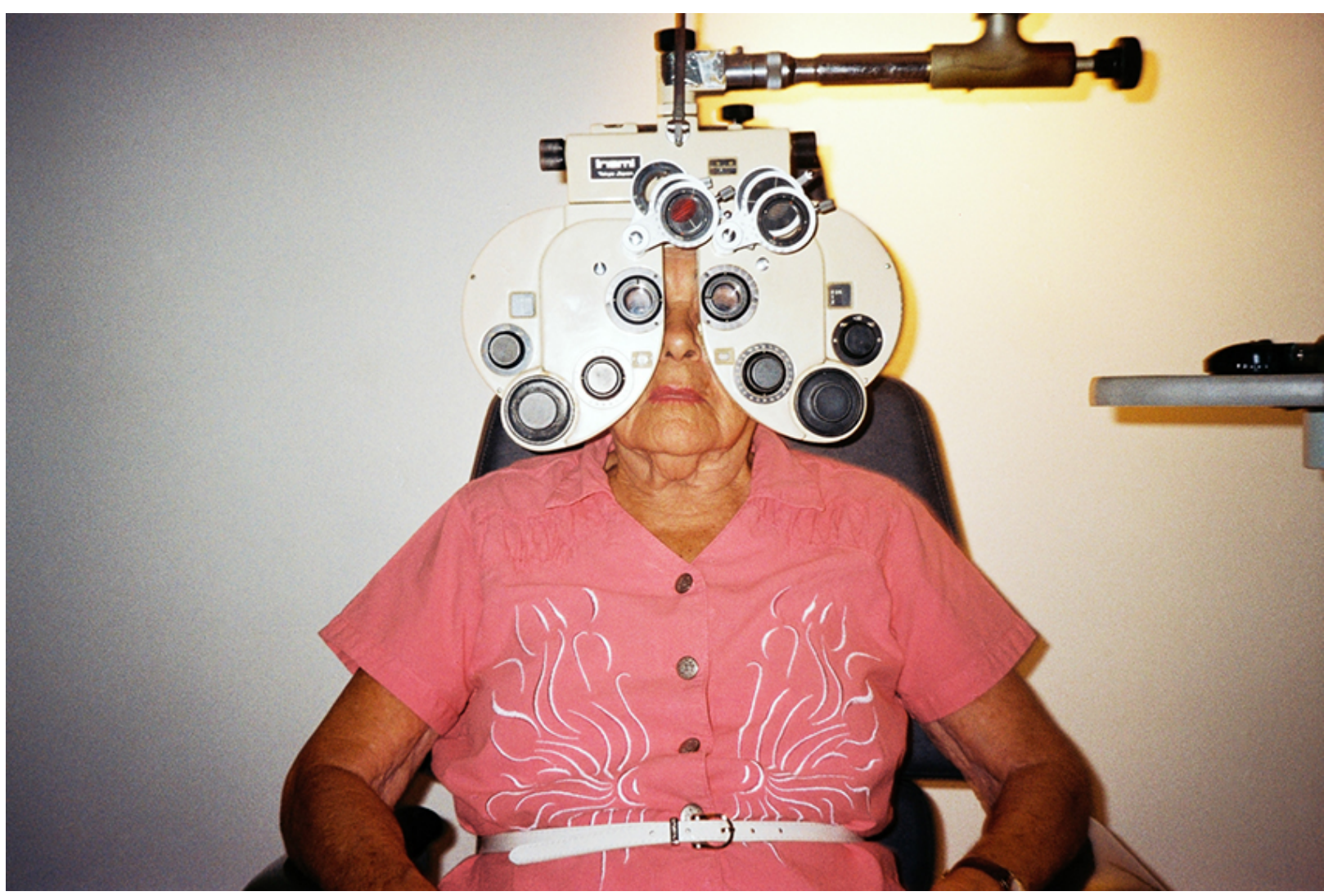

Para que possamos pensar sobre modos de vida outros, em particular a velhice artista, ampliar perspectivas acerca da multiplicidade de diferentes formas de ser e estar no mundo na velhice, para além de modelos normativos, interessa-nos adentrar nas fotos produzidas a partir de um encontro, ou melhor, de um bom encontro entre avó e neta. Duas gerações, dois modos de 
ser e estar no mundo, uma aumentando a potência de ação da outra pelo afeto, fomentando a criação, inventividade, e articulando a vida numa dimensão estética.

Adelaide Ivánova nasceu em Recife no ano 1982, já a sua avó, em um lugar qualquer do interior de Pernambuco em 1921. O nome dela é Adelaide de Queiroz e mora na área metropolitana do Recife, pôde estudar até a quarta série do fundamental, foi uma atriz de circo itinerante até o princípio da década de quarenta, casou-se e teve dezesseis filhos. Passou a vender bolos para sustentar a casa depois que a mercearia do marido foi à falência, depois tornou-se costureira trabalhando em casa e, dentre outras ocupações, é uma leitora assídua. Ivánova é escritora, poeta, jornalista e ativista, atuando também com fotografia, tradução e publicação. Morou em São Paulo, e partiu para a Alemanha, em 2011, onde vive desde então, para estudar fotografia na Ostkreuzschule für Fotografie em Berlim.

Por volta de 2006, após algum tempo distante, a neta passou a fotografar a avó encenando sempre que voltava à sua cidade natal para visitá-la, a fim de se aproximar mais dela, passar mais tempo com ela, divertirem-se juntas ocupadas com algo diferente do habitual: a fotografia, seu universo particular. Somado a isso, tinha um desejo de documentar, de criar uma espécie de álbum.

Fotografá-la era uma forma da gente passar um tempo juntas, ocupadas com alguma coisa, e não fosse só eu ir lá na casa dela, comer cuscuz e tomar café, entendesse? Era um jeito da gente se divertir e se aproximar através de uma ferramenta que é muito minha, é meu universo. Começou com isso: para se divertir. E tinha uma vontade também de documentar. (...) então tinha também um desejo de criar alguma espécie de álbum. (IVÁNOVA, 2017). 
Os encontros fotográficos se tornaram, portanto, a atividade principal, mais que isso, um catalisador dessa relação intergeracional e afetiva, favorecendo à ressignificação do vínculo afetivo.

Acho que o melhor que aconteceu na realização desse projeto foi realmente num âmbito muito pessoal: antes a minha avó era uma figura extremamente autoritária e isso foi um pouco se quebrando porque foi a primeira vez que a gente se divertiu juntas. Isso é bonito, não é? A fotografia foi meio que o vetor de uma reconstrução de uma subjetividade que não havia antes. (IVÁNOVA, 2017).

Mais adiante, por ocasião de uma demanda da faculdade, em 2011 (Berlim), as fotografias da avó foram apresentadas aos professores que as acharam fascinantes e ali apontaram um protoprojeto, "um desejo de falar sobre ela e sobre envelhecer"01. A partir daí Ivánova começou a fotografá-la de fato com intuito de projeto, ou seja, com uma maior concentração e preocupação estética. Além de compartilharem o mesmo nome, neta e avó passaram a criar de forma coletiva, numa dupla performance, esse projeto contínuo. Cabe lembrar que, apesar do vínculo consanguíneo, Ivánova fotografava a avó sem idealizações, no entanto se coloca em cena a todo momento, como se fizesse um autorretrato, pois se vê muito nela, no jeito falante de ser e na teimosia ${ }^{02}$.

O processo foi espontâneo e simples, Ivánova habitualmente usava uma câmera compacta, do tipo point and shoot, filme de

01 Citação de Adelaide Ivánova extraída da matéria do site Catraca Livre. https:// catracalivre.com.br/quem-inova/avo-e-neta-fazem-fotos-sobre-amor-e-envelhecimento/. 02 Do texto: http://meusdedoscruzados.blogspot.com/2011/10/vodca-com-adelaideivanova.html. 
$35 \mathrm{~mm}$, dos mais baratos e fáceis de encontrar, para fotografar Adelaide a qual encenava do seu jeito e conforme sua vontade. A maioria das pautas foi sugerida pela avó, por vezes, através de uma ligação inusitada: "querida, eu vou ao oftalmologista, você não quer ir comigo não? Me fotografar?" Desse modo a dupla desvia da normalidade do cotidiano transformando uma visita médica de rotina em um gesto criativo onde qualquer lugar poderia servir de campo de ação. Conforme o tempo passava, os movimentos e a resistência de Adelaide diminuíam, deixando as ações mais circunscritas no lado de dentro, sobretudo no ambiente doméstico, que pode ser a sala, o quarto, a cozinha, o quintal.

Com o passar do tempo, que a mobilidade foi ficando cada vez mais reduzida, ela não consegue mais ficar tanto tempo em pé, a gente teve que ficar mais tempo dentro do ambiente doméstico dela. Antes a gente saia, né? Fomos ao oftalmologista, tem foto dela na fisioterapia, na praia, mas com o tempo a gente começou a encenar dentro de casa e se reinventar mesmo criando essas cenas dentro de casa. (IVÁNOVA 2017).

Por quaisquer razões, para grande parte da população mais velha sobretudo para os denominados "velhos, velhos" (a partir de 85 anos), o ambiente domiciliar significa o lugar em que passam mais tempo quando não é o único, de maneira que a experiência com o espaço urbano seja mínima quando não nula.
É no espaço urbano que se realizam e se criam as principais realizações humanas. A ciência, a arte, a tecnologia, a economia, a organização social, a subje- tividade, a cultura como um todo, enfim, são forjados e forjam a cidade, essa morada contemporânea da humanidade (CORREA, 2016, p.37). 
O medo da violência urbana e os problemas de acessibilidade e mobilidade nos espaços, como calçadas desniveladas e esburacadas, são alguns fatores que dificultam a interação com a urbe, todavia os entraves sociais são capazes, igualmente, de dificultar profundamente a produção de subjetividade de pessoas velhas quando são demarcados quais os espaços que elas devem ocupar e como devem ocupar.

Neste caso, faz-se necessário desenvolver formas de sociabilidade que promovam a apropriação da cidade e circulação desses sujeitos para além dos "guetos etários", isto é, lugares que estão claramente demarcados por fronteiras etárias e sociais, a saber, espaços de casais, jovens, crianças, idosos, onde a circulação de um em espaço dos outros dificilmente ocorra (CORREA, 2016, p.43-44). Aliás, as formas de sociabilidade dentro do próprio grupo "velhice" apresentam diferenças geracionais, para os "velhos jovens" (os ditos idosos) o espaço social de interação predominante é mais o público, enquanto para os "velhos, velhos" é mais o doméstico senão asilar (CORREA, 2016, p.38). Não nos esqueçamos de que mesmo no ambiente doméstico (familiar), as relações interpessoais e afetivas entre gerações podem ser frágeis e distantes. Cabe ressaltar que esse distanciamento entre gerações mais indiferença e individualismo são efeitos colaterais do ato de subdividir e classificar a sociedade -como forma de controle- que criaram impacto negativo nas relações intergeracionais (entre duas ou mais gerações) ${ }^{03}$.

Além dos aspectos subjetivos, sociais e do espaço físico da dinâmica do envelhecer na cidade, aspectos que se referem aos limites físicos corporais também atravessam a relação com a cidade, como no caso de Adelaide cuja experiência urbana é mais restrita por causa das mudanças do corpo na velhice, inclusive. $O$ corpo pode ficar mais vagaroso, menos firme, podendo precisar de suporte de apoio, o que pode causar mais insegurança para circular nas calçadas das cidades ou, até certo ponto, não conseguirem se sustentar em pé por muito tempo, podendo gerar o receio de cair.

Para quem precisa, como Adelaide, ou escolhe viver principalmente do lado de dentro, a casa é o abrigo do mundo, de maneira a ser um lugar que estimule a vida, o acolhimento, a criação, o conforto, a segurança, e não uma prisão ou um confinamento. "Sentir-se confortável transcende o conforto físico que móveis e cômodos podem oferecer. O conforto é interior, emotivo e pessoal, construindo relações afetivas com suas "coisas", sejam as lembranças, a decoração

03 Da fala do psicólogo José Carlos Ferrigno

para o portal do envelhecimento. https://

www.portaldoenvelhecimento.com.br/ intergeracionalidade-das-relacoes-as-praticas-sociais/. 
e a bagunça pessoal" (MENDES, 2007, p.67). O mundo é identificado através de todos os sentidos pelo indivíduo, o qual percebe e experimenta a organização do espaço e a existência dos objetos por meio do contato, da manipulação e movimentação. Nesse sentido, o corpo (mente-cérebro) se relaciona com o ambiente transmitindo informações, emoções, sentimentos.

A casa é o lugar para onde a neta vai reencontrar a sua avó e os cheiros que ela conhece; para selar o abraço atrasado. A avó é casa. Para a avó a casa é onde ela passa mais tempo, é o lugar das suas realizações cotidianas e dos encontros com seus afetos. "Pois a casa é nosso canto do mundo. (...) É um verdadeiro cosmos. Um cosmos em toda a acepção do termo" (BACHELARD, 1978, p.200). É nesse cosmos que ambas compartilham e desdobram a experiência estética, reinventando-se e ressignificando a relação, bem como a velhice e o envelhecer.
Fotografia 2.

adelaide-02, Adelaide Ivánova. Fonte: ade-

laideivanova.com/ projects/adelaide/.

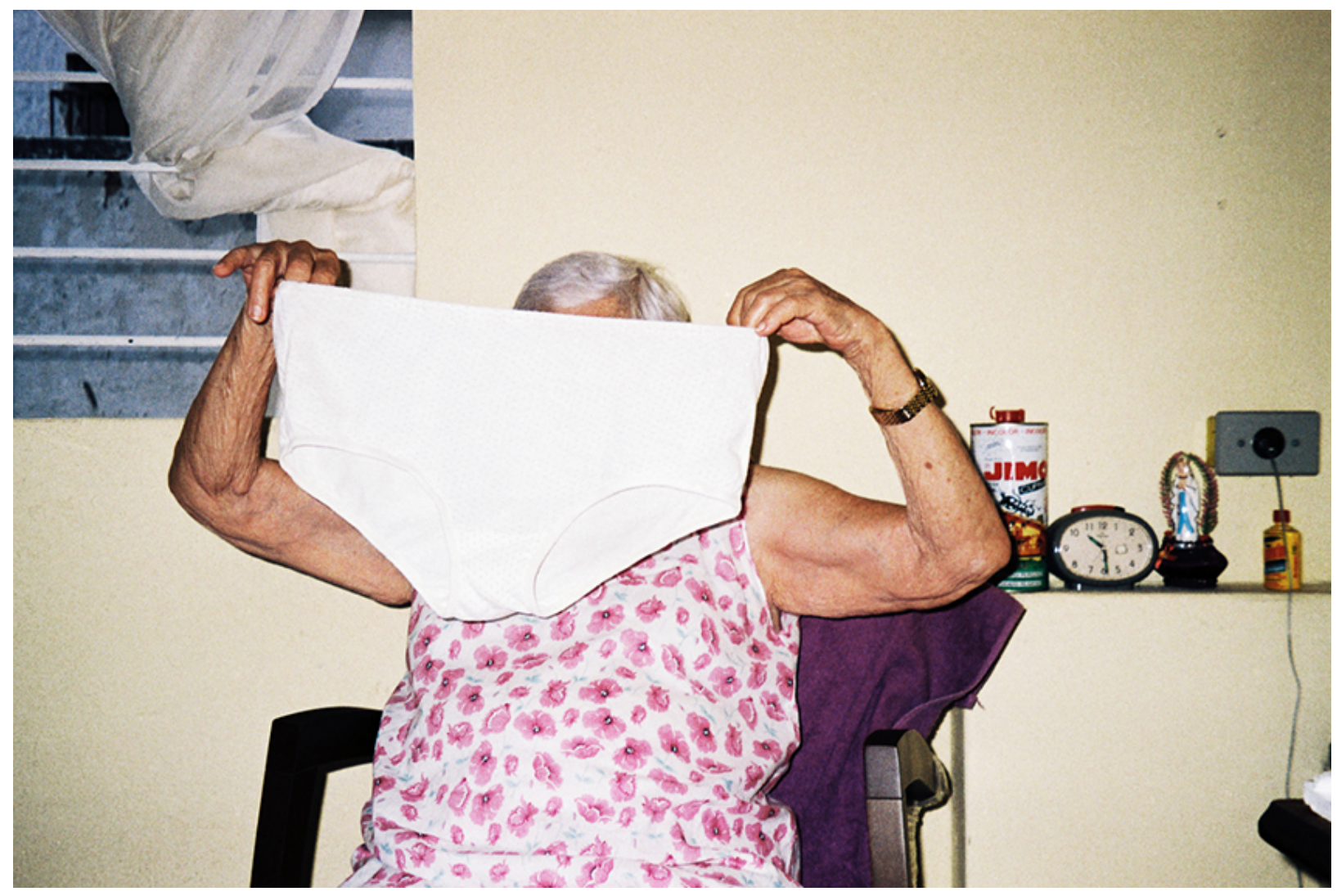


Adelaide está sempre em relação com o seu ambiente e com os artefatos que o compõem, o que torna a casa uma espécie de coadjuvante; um corpo que vibra. Santa, bacia, bandeira, Jimo, copos, cortina, planta, flores, espanador, roupa, lençóis, toalhas, vaso, vassoura, garrafa, quadros, relógio, martelo, tudo isso imprime a marca da moradora da mesma maneira que estão dispostos na cena como estratagema de composição do "cenário" (da caixa cênica). Dubois (2012) denomina cenário como toda uma série de elementos que ajudam a compor o quadro,

portas ou janelas, mais ou menos entreabertas; fundos, ou fundos duplos, de cena, espelhos; quadros, recortes de todos os tipos; em suma tudo o que pode indicar ou introduzir dentro do espaço homogêneo e fechado do campo fragmentos de outros espaços, em princípio contíguos e mais ou menos exteriores ao espaço principal (DUBOIS, 2012, p.187).

Acontece igual na série delas, elementos que apontam o lado de fora; janelas e portas pelas quais os cheiros e barulhos da rua invadem o lar se misturando aos dela. Barulhos estes que, inclusive, percebemos ainda mais quando ficamos mais tempo dentro dela (seja por imposição, seja por opção). Pensamos agora na Casa Tomada, de Julio Cortázar, e naquela foto que a figura de Adelaide estende a bandeira vermelha logo abaixo da janela entreaberta na cozinha, onde muitos dos outros sons como sirenes, alarmes, burburinhos, latidos ansiosos ou motores urgentes engrossam o coro dos demasiados barulhos de utensílios, vidros, chiados dos preparos, do café na cafeteira, que há na cozinha. Poderíamos supor, da mesma maneira, que se olhássemos do sentido inverso, daquele de quem vem de lá assim como quem volta, essas janelas mais portas e quadros fossem uma espécie de passagem secreta para um cosmo. Melhor, um portal que nos levassem para um cortejo em comemoração à deusa ursa, quem sabe para um carnaval inteiro dentro da sala ou quintal, ou para uma passeata no meio da cozinha.

O projeto, que recebeu o nome adelaide, é composto por vinte e quatro fotografias coloridas horizontais, com exceção de apenas 
uma na vertical, as quais se encontram tanto lado a lado quanto abaixo umas das outras, no site pessoal de Ivánova. Virtualmente, a experiência de corpo de caminhar pela exposição é concentrada nas mãos, especialmente nos dedos, que acionam o rolamento da página para subir e descer a galeria de fotos, que deslizam as imagens (em caso de tela touchscreen). Outro jeito de andar por lá é dando um clique ou toque para ampliá-las, apenas uma por vez no centro da tela, podendo ser passada no carrossel.

Em adelaide, a fotografia é uma ferramenta colocada a serviço de uma dupla experimentação criativa, de uma narrativa, de uma teatralidade que joga com a ambivalência- ficção e verdade- dela. A fotografia encenada é um terreno de experiência estética profícuo onde é possível criar ficções, contar histórias, fabular, e que desconstrói, por meio dos usos de determinados símbolos, como deslocamento das cenas narrativas, da composição, do uso de acessórios, luz, cenários, encenação com artefatos originais, expressão corporal etc., essa noção de fotografia comprometida, apenas, com o realismo e objetividade. 


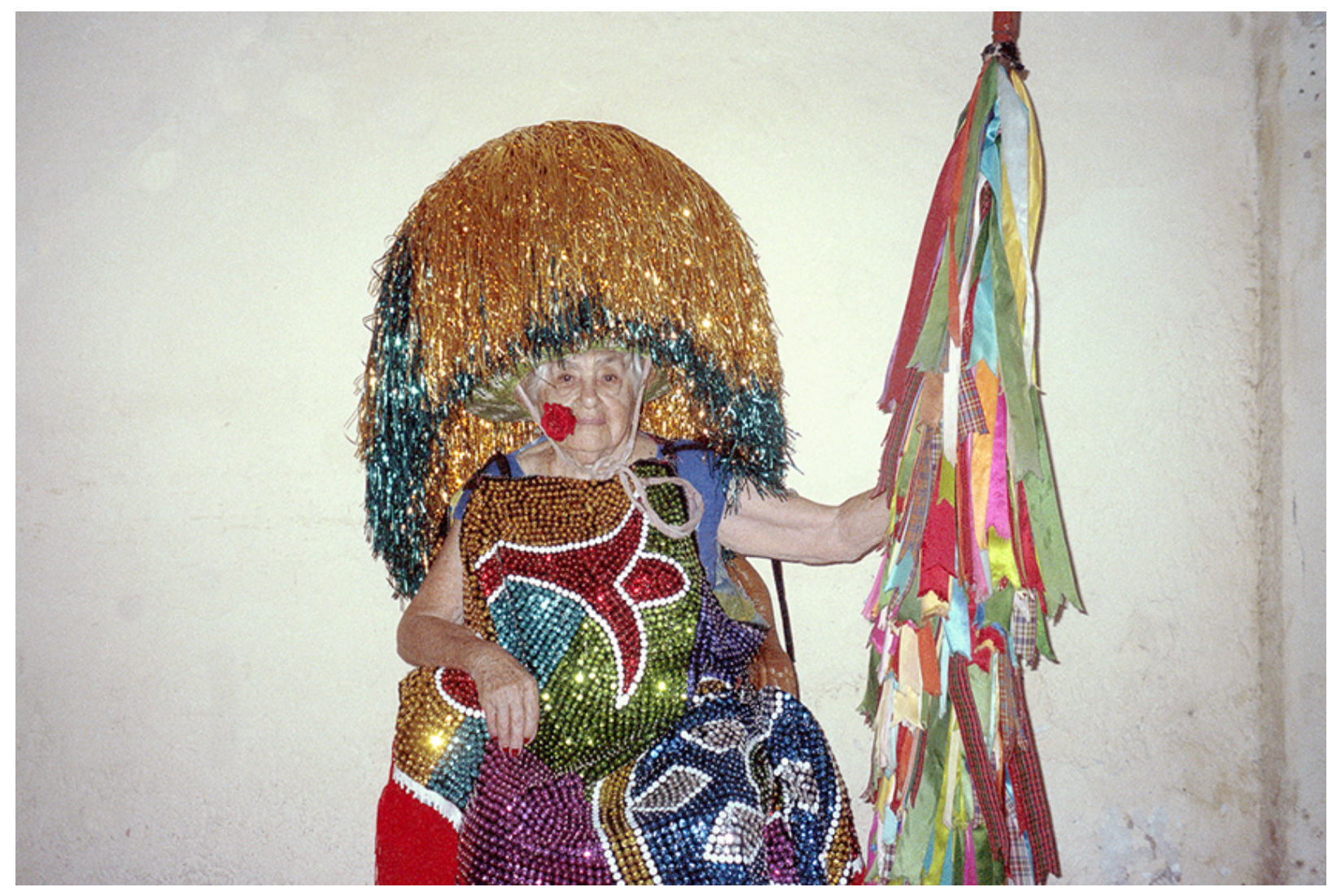

A série sobre a avó é poética e afetiva que nos sensibiliza, punge-nos pela sua vibração, autenticidade e força, incita à reflexão sobre a velhice, sobre nossas próprias vidas e relações próximas, onde o humor e a alegria são particularidades fortes, mas também uma certa melancolia e o tom mais sério. As fotos, aliás, não condizem com certos retratos tradicionais ou estereotipados de pessoas muito velhas. Quando, por exemplo, numa atitude de humor, Adelaide exibe sua confortável calcinha, subverte a ordem do comportamento esperado das pessoas mais velhas. Da mesma maneira acontece quando porta a vestimenta majestosa dos caboclos de lança (figura importante do carnaval rural de Pernambuco), geralmente vestida por homens; ou quando veste a máscara de la ursa- artefato popular no carnaval de

Fotografia 3.

adelaide- 15-1, Ade-

laide Ivánova. Fonte: adelaideivanova.com/ projects/adelaide/. rua pernambucano- numa performance elegante do que imaginamos ser uma espécie de ser híbrido, como as deusas egípcias com corpo de mulher e cabeça de animal. É possível confirmar que elas escacham as fronteiras de geração, de gênero, de comportamentos morais e etários "criando uma fenda aberta aos fluxos" (TÓTORA, 2015, p.40). 


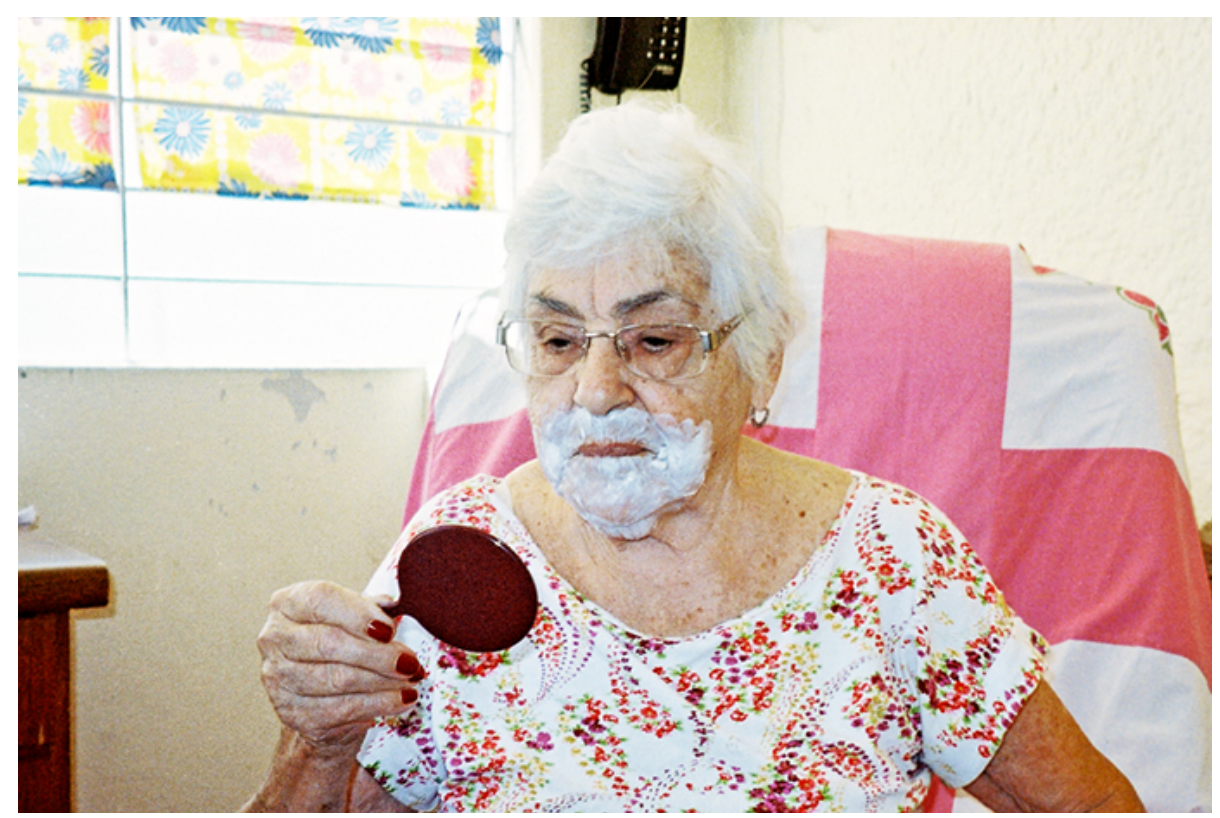

\section{Fotografia 4.}

adelaide-07, Adelaide Ivánova. Fonte: ade-

laideivanova.com/

projects/adelaide/.

\section{Fotografia 5.}

adelaide-18, Adelaide Ivánova. Fonte: adelaideivanova.com/projects/adelaide.adelaide/.

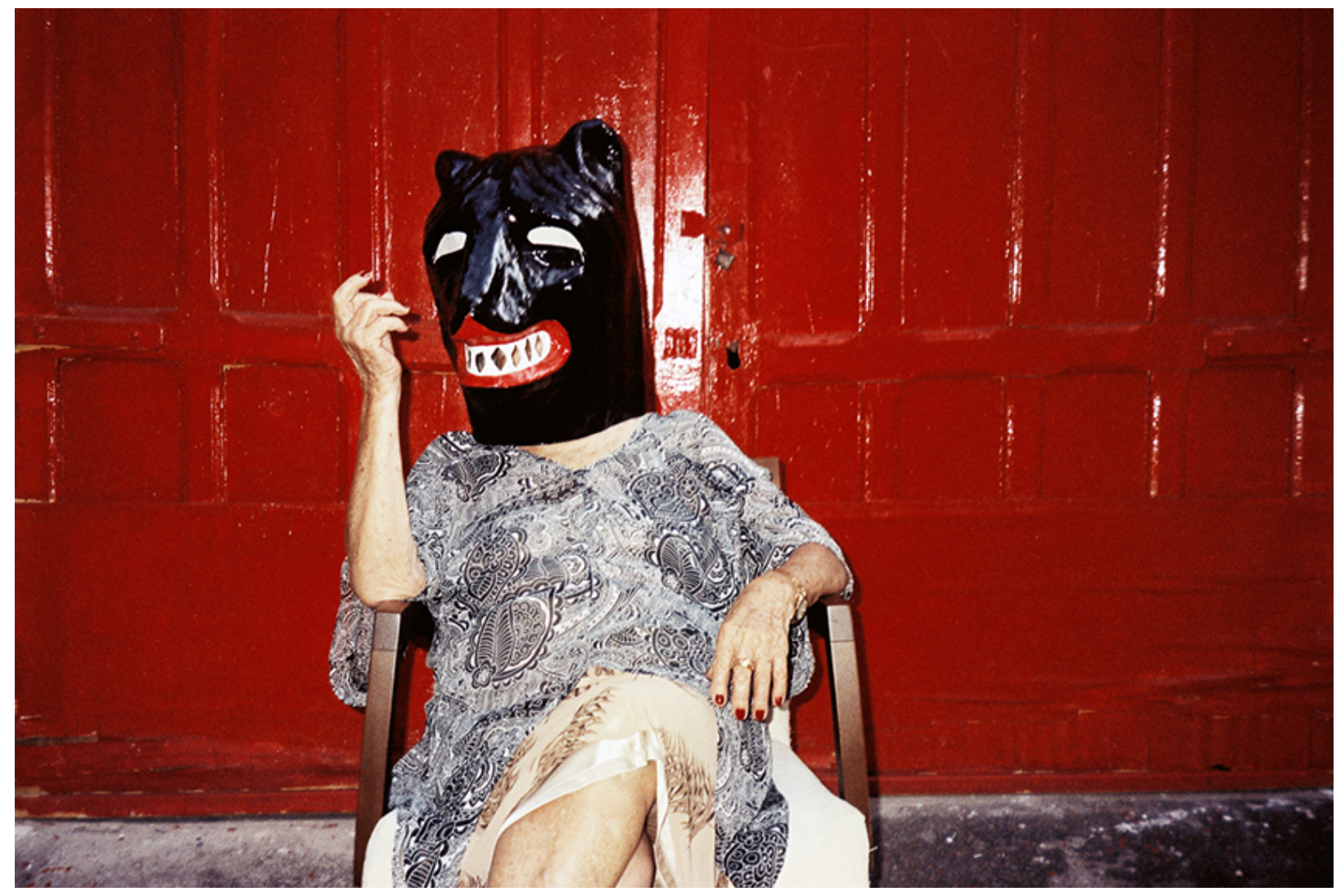

fronteiras do design. [entre] outros possíveis 
ocupa um lugar central nas fotos, seu corpo sempre está, o corpo em performance. Um corpo que não é eclipsado, ao contrário, o rosto que se encara diante do espelho, o corpo com sua pele crispada e suas dobras, que não se sustenta por muito tempo em pé, é colocado em cena junto à sua bengala e andador. À medida que avança a idade o corpo vai perdendo o viço, fica mais contido, os olhos se sobressaem. Na velhice o corpo é concentrado nas mãos e nos olhos pelos quais forças outras são exprimíveis, "e por eles se constroem relações e se estabelecem encontros." (TÓTORA, 2015, p.171).

Essa correspondência entre a velhice e os olhos e as mãos está tão evidenciada na narrativa pelas expressões faciais que dão o tom dos sentimentos e emoções como alegria e raiva, pelos gestos econômicos, contudo potentes, que exprimem qualidades e humor. Por causa da mobilidade da avó elas precisaram se reinventar, bem souberam trabalhar dentro das possibilidades corpóreas de Adelaide, buscando rotas criativas de ação nas potencialidades do corpo e para além dele.

Como mencionamos anteriormente, os sentimentos, emoções, qualidades, humor são exprimíveis nas expressões faciais e nos gestos, porém não são só neles, outros artifícios, como objetos e acessórios, são articulados para acionar ou expressar algo, por exemplo, o pisca-pisca em cima dela como se ela fosse a própria árvore de natal. Se por um lado as atitudes irônicas, as risadas, acessórios, as poses, o uso de objetos comemorativos podem indicar o humor, a agudeza dos olhos é a maior expressão quando o sorriso ou uma atitude alegre é suspensa.

Numa fotografia Adelaide está iluminada como naquelas cenas decisivas de cinema- o clímax da trama- onde tudo depende de um último gesto da personagem principal, então tudo vai silenciando, escurecendo até que o único ponto luminoso é ela. A figura dela está sorrindo apoiada em seu andador, à vontade de chinelos, vitoriosa com a bola sob os pés impedindo o gol. Essa atmosfera lúdica, de lazer a noite, no que parece ser um campinho de futebol de um edifício, é arrancada pela força bruta da expressão de Adelaide na fotografia seguinte. Ela se encontra no centro do enquadramento, lábios fechados, texturas de flores e frutas, uma luz tranquila e cores serenas, num clima doce que imaginamos ser da manhã. Todavia tem os 
olhos: dois vórtices nos atraindo para eles ao mesmo tempo que nos fustigam. Eis o ponto de tensão, uma atmosfera tão aconchegante e silenciosa em conflito com aquela expressão. Buscam-se pistas.

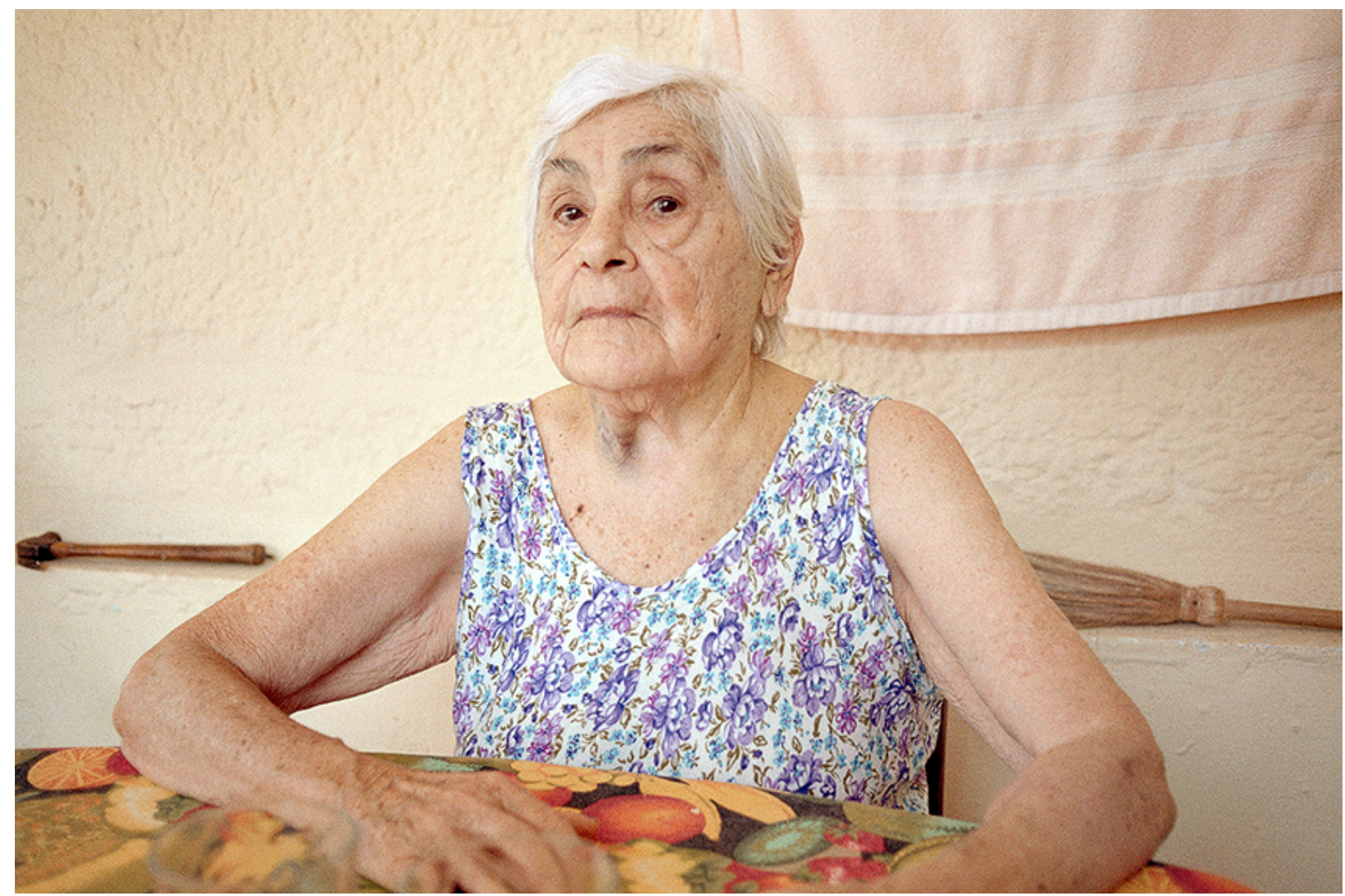

Atrás de Adelaide, do lado esquerdo, tem um objeto: o martelo, uma ferramenta manual e nome do segundo livro de Adelaide Ivánova o qual fala sobre a opressão e violências contra as mulheres (estupro, desprezo, silenciamento). Em síntese, é um livro que diz respeito ao que é imprescindível falar, sem subterfúgios, igualmente se refere aos corpos, tanto o da mulher quanto o da poesia, "que urgem por se libertar dos

Fotografia 6.

adelaide- 17, Adelaide Ivánova. Fonte: adelaideivanova.com/ projects/adelaide/. 
julgamentos que se colocam sobre eles" (ALMEIDA, 2017, p.71). O martelo é título do primeiro e do último poema do livro que começa assim: "durmo com um martelo/ embaixo do travesseiro/ caso alguém entre de novo/ e sorrateiro", e termina com fina ironia dos seguintes versos, "o martelo/ é um objeto ótimo/que serve pra dormir bem/ou pregar pregos" (IVÁNOVA, 2017, p. 11-70).

Versos de um corpo sempre atento, que se defende, mas também pode atacar. Por essa chave de leitura a expressão séria de Adelaide, que já arrebata à primeira vista despertando uma emoção incômoda, expande-se em sentidos, de modo que seu semblante ganha aspecto de raiva e indignação, e seus olhos endossam o estampido do martelo, também não se calam diante das mais variadas formas de violências e opressão contra determinados corpos sejam jovens ou velhos. Eles gritam.

Nessa foto nos parece evidente que há uma marca da ambivalência, que começa na própria fotografia encenada, pois os elementos são conectados por dissonâncias por dissonâncias, na qual raiva, indignação, violência, barulho são articulados com luz mansa, silêncio e texturas que exalam doçura, escapando das soluções óbvias. Ocorre também quando trata a ausência com presença, de modo lúdico, com objetos e atitudes que emitem graça. A propósito, esse jogo de esconder e mostrar dão movimento e ritmo à narrativa, bem como as posições (sentada, em pé) e posicionamento das mãos e braços (braços abertos, apoiados, mãos na cintura, apoiados, mão erguida, braços cruzados, mão no peito). 


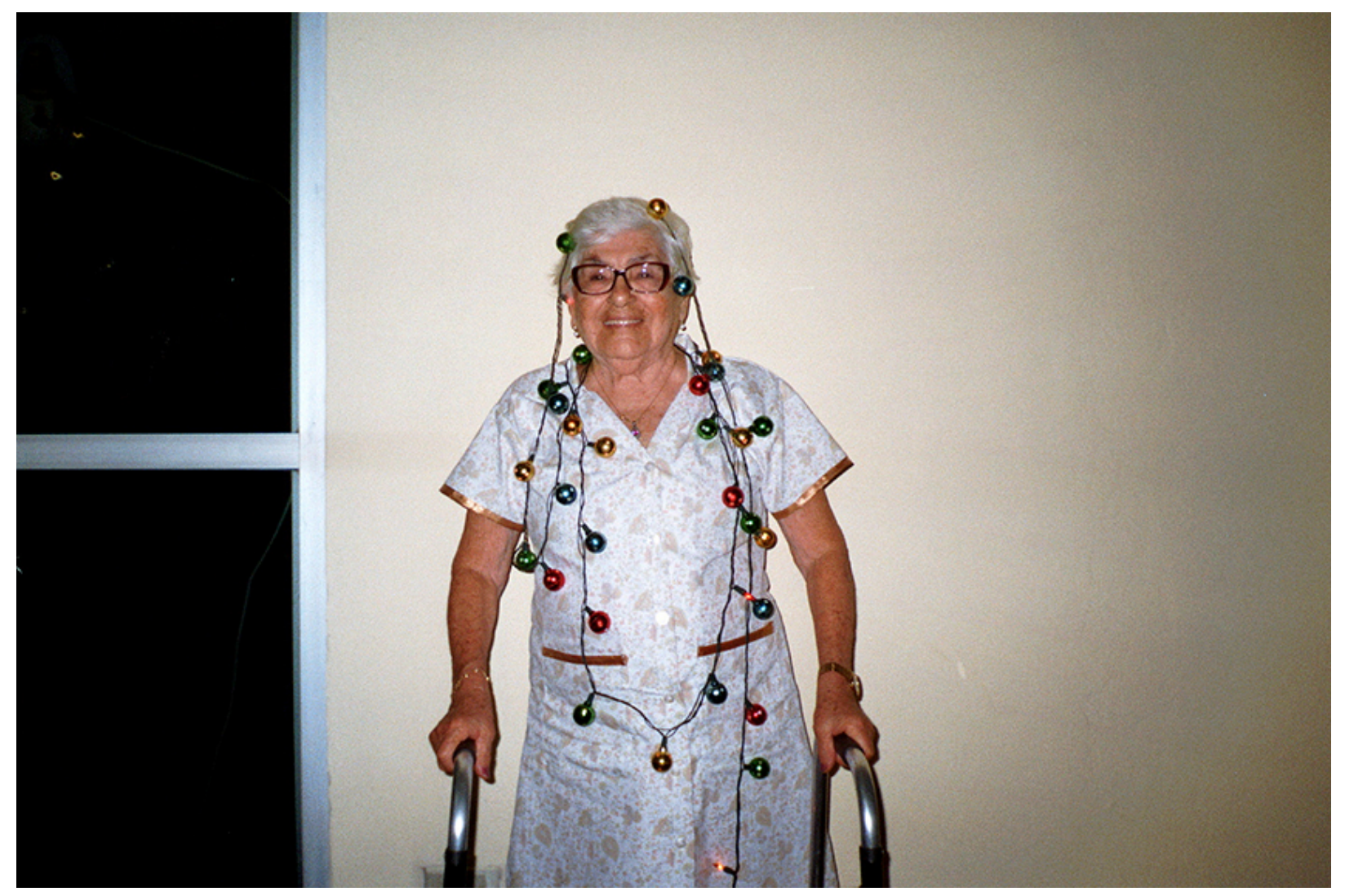

Destacamos ainda dois momentos sequenciais, no primeiro Adelaide está num cômodo hospitalar de uma luz quase fria e uma cor próxima do silêncio. Acomodada numa poltrona tomando iogurte de morango, com os olhos cansados dos enfermos, porém firmes. 0 assombro da morte. Na seguinte ela, aguerrida, porta a vestimenta colorida e brilhante de caboclo de lança, com seu chapéu, sua guiada e flor vermelha na boca, as quais simbolizam bênção e proteção. Assombro da vida.

Na narrativa há uma espécie de jogo, mostrar e ocultar o rosto ou parte dele através de objetos é o jogo de ocultar o rosto ou parte dele através de artefatos, a saber, óculos de sol, bandeira política, jornal, roupa íntima, máscara de la ursa, aparelho oftalmológico, bacia, creme ou espuma em volta da boca, para falar, de forma lúdica, sobre ausência, que pode ser quando Ivánova retorna para Alemanha. Nesse sentido, o uso das duas únicas fotos sem a figura de Adelaide, a do felino que supomos ser dela, e do antúrio talvez sua flor predileta, para falar da ausência especificamente da avó por questões

Fotografia 7.

imm029_31, Adelaide Ivánova. Fonte: adelaideivanova.com/ projects/adelaide. 
relativas à saúde, por exemplo. Também podemos observar um jogo com a intimidade, visto que as fotografias de Adelaide em trajes mais social, elegante, majestosa, são intercaladas ao visual e atitudes mais despojadas e íntimas (camisetas, chinelos, roupão, calcinha, espuma de barbear no rosto).

Ainda no que se refere à construção da narrativa, o uso alternado das performances com objetos que apontam tanto à época natalina- bola de natal, pisca-pisca- quanto ao carnaval (máscara de la ursa, indumentária de caboclo de lança, óculos de drinks) os quais consideramos ser os marcadores do tempo, um anúncio de quando avó e neta se reencontram, o que também significa presença. Cabe destacar que embora a figura de
Adelaide apareça sozinha em toda a montagem, é acionado, a toda hora, a presença de corpos outros, além da neta obviamente, seja pela bandeira política que alude ao coletivo, seja pelas referências ao natal que pressupõe à confraternização, e ao carnaval que remete à multidão.

Mais ainda: o carnaval é festa. É o prenúncio da liberdade, da liberação das normas, valores, hábitos. Oliveira (2007) argumenta, sob ressonância de Bakhtin (1997), que o carnaval é uma experiência vivida em que o princípio primordial é a liberdade se localizando nas mediações entre a vida e arte. Desse modo, "o carnaval é libertação temporária da verdade dominante e da ordem vigente, a abolição provisória de todas as 
realizações hierárquicas, privilégios, regras e tabus" (OLIVEIRA, 2007, p.80-81). Ora, a experiência estética de Adelaide tem a ver com esse imbricamento da vida e arte, que nem o carnaval, suspende o estado habitual e a ordem. O carnaval, além de expressão da cultura de onde nasceram, tem relação com o próprio processo delas, visto que é da natureza do carnaval festejar, enfeitar-se, transformar-se em personas, ser flor, ser gato, ser rainhas, ser brincante.

Outra coisa a ser observada concerne a dois elementos que chamam atenção na montagem, uma bandeira vermelha estendida com o nome da ex-presidenta do Brasil Dilma Rousseff e o nome do vice apagado abrindo a série, e o jornal com a notícia da morte do ex-presidente cubano Fidel Castro se sobrepondo no rosto dela, os quais escondem parte do corpo para revelar uma perspectiva política de esquerda, mais que isso, Adelaide se expressa e age politicamente, impõe seu direito à fala, indo contracorrente ao senso comum de que pessoas velhas, tanto quanto as crianças, precisam de chancela e/ou tutela. O que ocorre é que, na nossa sociedade, são silenciadas ou não se consideram as vozes nem das pessoas velhas, em especial dos "velhos, velhos", tampouco das crianças, que por sinal poderíamos nos inspirar mais na natureza imaginativa, força receptiva à criação e inventiva delas.

De modo geral a experiência fotográfica da série adelaide não foi só uma forma de estreitamento dos laços, mas também um território sem fronteiras, que trouxe para a vida cotidiana de Adelaide essa experiência estética (mais de dez anos), possibilitando esse elo com o exercício artístico de fabular, de se expressar, elaborar as cenas, as composições, as expressões corporais cada vez mais desafiadoras para a nonagenária com dificuldades locomotoras. Por isso ela geralmente está sentada ou apoiada em sua bengala e andador, porém tem seu viço e potência. Aliás, o que pode o corpo velho? O que pode a velhice? 


\section{VELHEZ}

Estamos vivendo mais e por mais tempo, nossas avós vivem mais que as avós das nossas mães (estima-se que alcançaremos os cento e cinquenta anos), percebam, testemunhamos a longevidade da juventude. $O$ que ocorre é que tudo isso tem mudado o modo como convivemos tanto na esfera particular quanto social. Atravessamos uma época de modificações de corpos pela biologia e não só dos corpos, mas da própria biologia; de dispositivos tecnológicos que transformam nossas relações consideravelmente. Vivemos em tempos de grandes avanços tecnológicos, ainda que o acesso à tecnologia exclua considerável número de pessoas. São tempos que se desenham como novas configurações e, no entanto, os mecanismos de modulação da existência se perpetuam, destarte a velhice e o envelhecer continuam sendo alvos de dispositivos de agenciamentos da vida.

Diante disso, abrir-se às possibilidades da velhez: uma [d]obra de arte de uma existência,

(...) para roçar a vida como intensidade e, assim, experimentar algo grande demais que promova um corte, criando uma cesura no curso do tempo cronológico (ou curso da vida). E, com a coragem dos que estão dispostos a correr o risco de viver, irromper numa outra temporalidade e encontrar as potências do tempo e a intensidade do devir, pois o estar entre a vida e 
a morte não é somente ao pé da letra estar próximo da morte, mas, sim, um entretempo onde tudo pode acontecer. (TÓTORA, 2017, p.257).

Velhez é um neologismo do poeta Manoel de Barros que Tótora não só adota, mas também o reivindica em lugar de velhice e idoso, palavras, segundo ela, não potentes. Todavia, é interessante notar que o uso das palavras velho, velha, velhez, como Tótora entre outros, sugerem e reivindicam ser usadas de forma potente e afirmativa, a palavra velho/a ainda é empregada para os mais pobres, os que buscam serviços públicos de saúde ou tomada para insultar. Para a autora a palavra idosa/o soa solene demais, porque idoso the remete à sabedoria, uma sabedoria adquirida no decorrer da vivência, e sabedoria acumulada provoca esclerose. Prefere adotar velhez cuja escrita promove um desvio da gramática normativa. A própria poesia subverte a linguagem, sobretudo, a gramática. Os versos do poeta são criados com as coisas inúteis, desimportantes, imprestáveis. E para sociedade, ainda, o velho é imprestável. A velhice só é aceitável se rejuvenescida, recauchutada. (TÓTORA, 2015, p.208). Então velhez se aproxima de um devir criança, no sentido de criança brincalhona, da alegria, da invenção, de dar início a algo novo.

Assim, é de total relevância as contribuições Tótora, bem como as brechas abertas para uma ética da velhice como obra de arte, especialmente a ética dos encontros para que os novos modos de vida emerjam e se acentuem os bons encontros pelas diferenças. 


\section{AGRADECIMENTOS}

\section{As autoras agradecem à PROPG e à CAPES} pela alocação de 12 meses de bolsa, possibilitando a consecução da pesquisa de Mestrado.

\section{REFERÊNCIAS}

ALMEIDA, Carol. Posfácio. In: IVÁNOVA, Adelaide. 0 Martelo. 2a ed. Rio de Janeiro:

Edições Garupa, 2017. p.71-73.

BACHELARD, Gaston. A filosofia do não; O novo espírito científico; A poética do espaço. São Paulo: Abril Cultural, 1978.

BARROS, Regina Duarte Benevides; CASTRO, Adriana Miranda de. TERCEIRA IDADE: o discurso dos experts e a produção do "novo velho". Estud. interdiscip. envelhec., Porto Alegre, v. 4, p. 113-124, 2002. Disponível em: https://seer.ufrgs.br/RevEnvelhecer/article/ viewFile/4723/2648>. Acesso em: 10 out. 2017.

CORREA, Mariele Rodrigues. Envelhecer na cidade. Revista Espaço Acadêmico. n.184- setembro/2016-mensal- p.35-46. Dossiê subjetividade e cidades- Ano XVI. Disponível em:< http://www.periodicos.uem.br/ojs/index. php/EspacoAcademico/article/view/32813>. Acesso em: 10 ago. 2017.

DELEUZE, Gilles. Cursos sobre Spinoza: (Vincennes, 1978-1981). Fortaleza: Ed. UECE. 2009. 
DUBOIS, Philippe. 0 ato fotográfico e outros ensaios. Tradução: APPENZELLER, Marina. 14a. ed. Campinas: Papirus, 2012.

IVÁNOVA, Adelaide. 0 Martelo. 2a ed. Rio de Janeiro: Edições Garupa, 2017.

OLIVEIRA, Lúcia Maciel Barbosa de. Corpos indisciplinados: Ação cultural em tempos de biopolítica. São Paulo: Editora Beca, 2007.

TÓTORA, Silvana. Velhice: uma estética da existência. São Paulo: EDUC: FAPESP, 2015.

TÓTORA, Silvana. Envelhecimento ativo: proveniências e modulação da subjetividade.

Revista Kairós- Gerontologia, [S.I.], v. 20, n. 1, (2017) p. 239-258. Disponível em: <https://revistas.pucsp.br/kairos/article/ view/2176-901X.2017v20i1p239-258>. Acesso em: 14 mar. 2018.

fronteiras do design. [entre] outros possíveis 
